\title{
Developmental Changes in Metacognitive Strategy in Japanese Elementary School Children
}

\author{
Ryo Okada ${ }^{1}$ \\ ${ }^{1}$ Faculty of Education, Kagawa University, Kagawa, Japan \\ Correspondence: Ryo Okada, Faculty of Education, Kagawa University, Saiwaicho 1-1, Takamatsu City, Kagawa \\ Prefecture 760-8521, Japan. E-mail: okada.ryo@kagawa-u.ac.jp
}

Received: March 15, 2021

Accepted: June 10, $2021 \quad$ Online Published: September 30, 2021

doi:10.5539/ies.v14n11p1

URL: https://doi.org/10.5539/ies.v14n11p1

\begin{abstract}
This study investigated developmental changes in metacognitive strategies during elementary school years and examined the effects of intrinsic motivation on metacognitive strategies. A total of 113 Japanese elementary school children participated in a three-year longitudinal survey with eight times measurement occasions. Multilevel modeling analyses showed that metacognitive strategies would linearly increase over three years. Intrinsic motivation was also related to metacognitive strategies in two ways: the initial status of intrinsic motivation was associated with the average level of metacognitive strategies. Further, the deviations from the baseline of intrinsic motivation were related to changes in metacognitive strategies. This suggests that intrinsic motivation impacts the development of metacognitive strategies.
\end{abstract}

Keywords: metacognitive strategy, intrinsic motivation, longitudinal data, developmental trend, elementary school children

\section{Introduction}

\subsection{Metacognition and Academic Achievement}

For effective learning, learners need to pay attention to their learning process. To monitor one's understanding, notice the mistakes, and control how to think or solve problems play essential roles in reaching academic achievement. These processes have been referred to as metacognition. Flavell (1979) defined metacognition as the person's knowledge and cognition about cognitive phenomena. Paris and Winograd (1990) assumed the two features of metacognition: self-appraisal and self-management of cognition. Although research literature holds some "fuzziness" of the concept and its constituents (Veenman, 2012), there is a consensus in focusing on the higher level of cognition about one's cognitive processes, including thinking or understanding.

Metacognition has been regarded as a multifaceted concept. Researchers have distinguished metacognitive knowledge and metacognitive skills (e.g., Flavell, 1979; Veenman, Van Hout-Wolters, \& Afflerbach, 2006). Metacognitive knowledge refers to one's declarative knowledge about the interplay between person, task, and strategy characteristics (Flavell, 1979). Metacognitive skills pertain to the acquired ability of monitoring, guiding, steering, and controlling one's learning and problem-solving behavior (Veenman, 2012). Moshman (2018) called the latter component as metacognitive control processes.

Some researchers have regarded metacognitive skills as a type of learning strategy. Metacognitive strategies have been a repertory of learning strategies that learners use in academic settings or problem-solving situations. Learning strategy is a sequence of procedures for accomplishing learning (Schmeck, 1988), and various strategies play critical roles in the academic achievement process. Regulating one's cognition or way to think is a kind of strategy that learners use to understand materials or solve problems. Some measurement tools include subscales that tap metacognitive strategies. For example, the Motivated Strategies for Learning Questionnaire (MSLQ: Pintrich, Smith, Garcia, \& McKeachie, 1993) is one of the essential tools to assess learners' motivation and learning strategies. It includes the subscale of metacognitive self-regulation as a metacognitive strategy. Some types of metacognitive strategies have been differentiated in each study. However, most studies set the components of planning, monitoring, regulating, and evaluation as metacognitive strategies (e.g., Dignath, Büettner, \& Langfeldt, 2008; Moshman, 2018).

Empirical studies have verified the relationships between metacognition and academic performance. A recent 
meta-analysis (Ohtani \& Hisasaka, 2018) revealed a positive correlation between metacognition and academic performance $(r=.28,95 \% \mathrm{CI}[.24, .31])$. This positive relationship remained after controlling for IQ. Dent and Koenka's (2016) meta-analysis reported a correlation of .24 (95\% CI [.15, .32]) between metacognitive processes, including metacognitive strategies and academic performance in samples of elementary school children. Therefore, it was suggested that learners who use more metacognitive skills or strategies in the learning process get higher grades.

\subsection{Developmental Changes in Metacognition during Elementary School Years}

Since about when children can use metacognitive strategies? There have been some debates about the developmental period and trend of metacognition during childhood. Some studies have shown that regulating their strategies is weaker in early childhood (Dufresne \& Kobasigawa, 1989). Children have limitations in monitoring their cognition (Markman, 1979). No clear standard for development in metacognition has been established, partly because of its broader definition. As with metacognitive strategies, its developmental trend has not been revealed. However, there seems to be a general consensus regarding the following points: (1) early children have little ability to use metacognitive strategies and (2) development in academic metacognitive strategies arises at the age of about 8-10 years old (Veenman, 2012). That is, elementary school years are critical periods for the development of metacognitive strategies.

Some researchers have shown differences among school grades or stages in metacognitive strategies. For example, Zimmerman and Martinez-Pons (1990) investigated 5th, 8th, and 11th-grade students' self-regulated learning strategies, including some metacognitive strategies, and compared the mean level of strategy use among the students. Roebers, Krebs, and Roderer (2014) revealed that older children (11 years old) compared to younger children ( 9 years old) showed superior metacognitive monitoring performance in experimental tasks assessing two metacognitive skills of monitoring and control. However, most previous studies analyzed not longitudinal but cross-sectional data. Thus, they did not approach how metacognitive strategies develop within individual children during elementary school years. It is assumed that children can acquire metacognitive strategies by instruction (Dignath et al., 2008). To examine the developmental trends in metacognitive strategies would propose a useful suggestion for educators to construct a grade-suited practical instruction that supports metacognitive strategies.

\subsection{Metacognition and Intrinsic Motivation}

It was supposed that the developmental changes in metacognitive strategies were affected by many factors in daily classroom experiences. This study focused on intrinsic motivation. Educational researchers have focused on intrinsic motivation as a factor that supports adaptive learning (Pintrich, 2003; Ryan \& Deci, 2000). Some researchers have examined the relationships between intrinsic motivation and metacognitive strategies. It has been suggested that higher levels of intrinsic motivation are related to more metacognitive strategy use (Vansteenkiste, Sierens, Soenens, Luyckx, \& Lens, 2009; Yamauchi, Kumagai, \& Kawasaki, 1999; Young, 2005). The children motivated intrinsically for daily classes would actively engage in the tasks and try to solve problems. In such active engagement, they learn to use metacognitive strategies through trial and error in problem-solving.

In terms of emotional experience in daily classes, intrinsic motivation would affect later metacognitive strategies. Ahmed, Van der Werf, Kuyper, and Minnaert (2013) revealed that classroom enjoyment, which can be an affective component of intrinsic motivation, predicted the development of metacognitive strategies in the sample of 7th-grade students. Positive emotional experiences would activate children's flexible thinking and motivate them to use metacognitive strategies.

However, few studies have examined the effects of intrinsic motivation on metacognitive strategies in elementary school children's samples. In particular, the effects of intrinsic motivation on the developmental changes in metacognitive strategies have not been addressed. If the relationship were verified, it would help educators consider a way to support children's metacognitive strategies from motivational theories.

\subsection{The Present Study}

The present study had two primary purposes. The first was to reveal the developmental changes in metacognitive strategies during elementary school years. The second was to find the effects of intrinsic motivation on metacognitive strategies. The hypotheses are as follows:

Hypothesis 1 . Metacognitive strategy increases during elementary school years.

Hypothesis 2 . The changes in intrinsic motivation are related to changes in metacognitive strategies.

Longitudinal data for three years were analyzed to test the two hypotheses. 


\section{Method}

\subsection{Participants and Procedure}

Participants were third- and fourth-grade Japanese children in an elementary school that was attached to a university. A total of 68 third graders and 70 fourth graders began participating in 2018. Third graders in 2018 are referred to as Sample 1, and fourth graders in 2018 are referred to as Sample 2. They answered questionnaires on eight occasions during three school years: May 2018 (T1), November 2018 (T2), February 2019 (T3), May 2019 (T4), November 2019 (T5), February 2020 (T6), July 2020 (T7), and December 2020 (T8). The school year begins in April and ends in March in Japan. Sample 1 had three measurement occasions in the third and fourth grades and two measurement occasions in the fifth grade. Sample 2 had three measurement occasions in the fourth and fifth grades and two measurement occasions in sixth grade. During eight measurement occasions, 20 children did not provide complete data because they were absent or changing school. Excluding the children, the final sample consisted of 53 third graders ( 28 boys and 25 girls: Sample 1) and 60 fourth graders (27 boys and 33 girls: Sample 2) were analyzed.

\subsection{Measures}

\subsubsection{Metacognitive Strategy}

Sato and Arai's (1998) Learning Strategy Scale was used to assess children's metacognitive strategy use. This scale was developed to assess some aspects of learning strategies for Japanese elementary and junior high school students and include cognitive and metacognitive strategies. In this study, 14 items tapping metacognitive strategies were adopted. The items were designed to assess the components of metacognitive strategies: planning (e.g., "I first plan what to do before studying"), monitoring (e.g., "When studying, I try to find where I cannot understand"), and self-regulation (e.g., "When I cannot understand, I change the ways to study"). The validitiy of the scale has been established in original study (Sato \& Arai, 1998). Participants were asked to rate each item on a 4-point Likert scale of 1 (almost never), 2 (rarely), 3 (sometimes), and 4 (almost always).

Although two factors emerged in the original study (Sato \& Arai, 1998), other studies gave different factor structures (Ichihara \& Arai, 2006; Suzuki, 2013). An exploratory factor analysis with the maximum likelihood method was administered to the data at T1. Eigenvalues were 7.94, 0.97, and 0.90 for each factor, and the value of MAP was the lowest for one factor; thus, a one-factor solution was adopted. All factor loadings were above .5 . Scale scores at each measurement occasion were calculated by averaging 14 item scores. The estimated reliability coefficients (McDonald's $\omega$ ) ranged from .92 to .94 .

\subsubsection{Intrinsic Motivation}

Okada's (2019) Intrinsic Motivation Scale was used to assess children's intrinsic motivation. The scale comprises six items covering intrinsic motivation's various features (Harter, 1981). The items are "It is fun to study," "I'm interested in what I study at classes," "when I attend classes, time passes fast," "I learn useful things for me," "I challenge difficult tasks," and "I want to learn various things more." The validity of the scale has been partly examined through exploratory factor analyses in the samples of Japanese elementary school children (Okada, 2019). Participants were asked to rate each item in remembering daily classes on a 4-point Likert scale of 1 (not true), 2 (rarely true), 3 (sometimes true), and 4 (true). Scale scores at each measurement occasion were calculated by averaging six item scores. The estimated reliability coefficients (McDonald's $\omega$ ) ranged from .83 to .89 .

\subsection{Analytic Procedures}

Multilevel modeling was used (Snijders \& Bosker, 1999) to examine the general developmental trends of children's metacognitive strategies and their relationship with intrinsic motivation. First, developmental changes in metacognitive strategies were examined. In the analysis, two-level multilevel models were tested. The level 1 model (within-children model) describes individual children's change trajectory with growth curve parameters: the intercept representing the children's initial status and the slope representing the children's growth rate. The level 2 model (between-children model) describes individual differences in these growth curve parameters. The effect of measurement occasions was estimated to examine the developmental trend of metacognitive strategies. About the effects of measurement occasions, linear and quadratic trends were examined. Furthermore, the main and moderated effects of the samples were estimated. Parameters were estimated using the maximum likelihood method.

Next, the longitudinal relationships between intrinsic motivation and metacognitive strategies were estimated. Longitudinal data were analyzed with multilevel modeling grounded on a hybrid model (Allison, 2009). The hybrid model is a multilevel model for longitudinal data. In the model, the individual-specific mean across measurement occasions is entered as a fixed effect at level 2, in addition to within-individual variables at level 1 
and between-individual variables at level 2 . This enables the partitioning between predictors' varying across times within individuals and the effects of predictors varying between individuals. For the sake of partitioning, individual-specific means are used as level 2 variables, and deviations from the individual-specific means are used as level 1 variable. The effect of individual-specific means at level 2 shows the effects of differences between individuals on the dependent variable. The effects of deviance at level 1 show the effects that predictors' effects have on the changes of dependent variables. Following Ahmed et al.'s (2013) procedure, the baseline score at T1 was used as a level 2 variable in place of individual-specific means, and deviations from baseline score at T1 were used as level 1 variable. This would ease the interpretation of the effects of the initial level of intrinsic motivation. The effects of intrinsic motivation on the developmental changes in metacognitive strategies were examined by analyzing the model. All analyses were administered using R version 3.6.1 and the nlme package for multilevel modeling.

\section{Results}

\subsection{Descriptive Statistics and Correlations Among Variables}

Descriptive statistics are presented in Table 1. Means across eight measurement occasions show that there appears to be a general increase in the mean level of metacognitive strategy in both samples. However, intrinsic motivation seems to be stable across measurement occasions. Intercorrelations ranged from .44 to .76 for metacognitive strategy and from .27 to .70 for intrinsic motivation. Correlations between metacognitive strategy and intrinsic motivation on the same measurement occasions ranged from .42 to .65 .

Table 1. Descriptive statistics for the study variables

\begin{tabular}{ccccccccc}
\hline & \multicolumn{3}{c}{ Metacognitive strategy } & \multicolumn{4}{c}{ Intrinsic motivation } \\
\cline { 2 - 9 } & \multicolumn{2}{c}{$\begin{array}{c}\text { Sample1 } \\
\text { (Grade 3rd to 5th) }\end{array}$} & $\begin{array}{c}\text { Sample 2 } \\
\text { (Grade 4th to 6th) }\end{array}$ & \multicolumn{2}{c}{$\begin{array}{c}\text { Sample1 } \\
\text { (Grade 3rd to 5th) }\end{array}$} & $\begin{array}{c}\text { Sample 2 } \\
\text { (Grade 4th to 6th) }\end{array}$ \\
\cline { 2 - 10 } & Mean & $S D$ & Mean & $S D$ & Mean & $S D$ & Mean & $S D$ \\
\hline T1 & 2.80 & 0.79 & 2.90 & 0.81 & 3.29 & 0.67 & 3.40 & 0.59 \\
T2 & 2.81 & 0.81 & 2.93 & 0.74 & 3.27 & 0.75 & 3.09 & 0.62 \\
T3 & 2.80 & 0.72 & 2.79 & 0.71 & 3.13 & 0.76 & 3.19 & 0.69 \\
T4 & 3.03 & 0.72 & 3.03 & 0.70 & 3.27 & 0.69 & 3.18 & 0.69 \\
T5 & 2.99 & 0.73 & 3.23 & 0.60 & 3.14 & 0.76 & 3.42 & 0.39 \\
T6 & 3.05 & 0.72 & 3.37 & 0.52 & 3.11 & 0.79 & 3.41 & 0.56 \\
T7 & 3.10 & 0.60 & 3.42 & 0.55 & 3.17 & 0.76 & 3.49 & 0.41 \\
T8 & 3.07 & 0.61 & 3.31 & 0.68 & 3.23 & 0.65 & 3.47 & 0.47 \\
\hline
\end{tabular}

\subsection{Developmental Changes in Metacognitive Strategies}

Developmental changes in metacognitive strategies were examined. First, the model with time and sample as predictors was tested. The model is as follows:

$$
Y_{i j}=\gamma_{00}+\gamma_{01}(\text { Sample })_{j}+\zeta_{0 j}+\gamma_{10}(\text { Time })_{i j}+\zeta_{1 j}(\text { Time })_{i j}+\varepsilon_{i j}
$$

$Y_{i j}$ represents the metacognitive strategy score, $\gamma_{00}$ and $\gamma_{01}$ are the effects of intercept and sample, respectively. The parameter $\gamma_{10}$ shows the effect of time. The symbols $\zeta_{i j}$ and $\varepsilon_{i j}$ represent the residual variance at level 2 and level 1, respectively. The subscripts $i$ and $j$ denote the measurement occasions and individuals, respectively. The sample was dummy coded (Sample $1=0$, Sample $2=1$ ). Eight measurements were not performed regularly, so the time intervals were varied. The time variable was coded as months passed from $\mathrm{T} 1$. That is, $\mathrm{T} 1=0, \mathrm{~T} 2=6, \mathrm{~T} 3=9, \mathrm{~T} 4$ $=12, \mathrm{~T} 5=18, \mathrm{~T} 6=21, \mathrm{~T} 7=26$, and $\mathrm{T} 8=31$ to reflect the variations. Thus, the effect of time suggested growth in a one-month unit.

The results are presented in Table 2. The fit indices were as follows: $\mathrm{AIC}=1399.96$ and $\mathrm{BIC}=1433.60$. In the model, time's effect was significant $(\gamma=0.015, p<.001)$, showing that the metacognitive strategy scores were higher on later measurement occasions. The increase in metacognitive strategy in a year was 0.18 (i.e., $0.015 \times 12$ months). The sample's effect was also significant $(\gamma=0.22, p<.001)$, showing that Sample 2 was higher than Sample 1. Squared time was entered to examine the quadratic change of metacognitive strategy. However, the model fit indices did not improve: $\mathrm{AIC}=1386.81$ and $\mathrm{BIC}=1439.69$, and the effect of squared time was not significant $(\gamma=-0.0001$, n.s., $95 \% \mathrm{CI}[-0.0005,0.0002])$. Next, the interaction term of time $\times$ sample was entered. However, $\mathrm{AIC}$ and $\mathrm{BIC}$ were not better $(\mathrm{AIC}=1379.86$ and $\mathrm{BIC}=1436.32)$ and the difference from the model 
without the interaction term was non-significant $\left(\chi^{2}=2.05, d f=1, n . s\right.$. $)$, although the interaction term showed a significantly smaller value $(\gamma=0.009, p<.05,95 \%$ CI $[0.0003,0.0178])$. This suggests that metacognitive strategies increase almost linearly from T1 to T8 in Sample 1 and Sample 2.

Table 2. Results of multilevel analysis of developmental changes in metacognitive strategy

Note. ${ }^{*} p<.05,{ }^{* * *} p<.001$.

\begin{tabular}{lccc}
\hline & Estimates & $S E$ & $95 \% \mathrm{CI}$ \\
\hline Fixed effects & & & \\
Intercept $\left(\gamma_{00}\right)$ & $2.70^{* * *}$ & 0.08 & {$[2.53,2.86]$} \\
Sample $\left(\gamma_{01}\right)$ & $0.22^{*}$ & 0.10 & {$[0.03,0.42]$} \\
Time $\left(\gamma_{10}\right)$ & $0.015^{* * *}$ & 0.002 & {$[0.011,0.020]$} \\
Radom effects & & & \\
Intercept $\left(\zeta_{0 j}\right)$ & 0.48 & & \\
Time $\left(\zeta_{1 j}\right)$ & 0.0004 & & \\
Within-children $\left(\varepsilon_{i j}\right)$ & 0.18 & & \\
\hline
\end{tabular}

\subsection{Longitudinal Relationship between Intrinsic Motivation and Metacognitive Strategy}

A longitudinal relationship between intrinsic motivation and metacognitive strategy was examined using multilevel modeling. Before the examination, the change in intrinsic motivation was tested with the same analysis as the metacognitive strategy. The effect of time was nonsignificant $(\gamma=0.003, n . s ., 95 \% \mathrm{CI}[-0.002,0.007])$.

Next, to the effects of intrinsic motivation on metacognitive strategy, two intrinsic motivation components were entered in the analytic model. The baseline score at $\mathrm{T} 1$ as an initial status was entered in level 2, and the deviations from the baseline score at $\mathrm{T} 1$ were entered at level 1. Moreover, time and sample were entered as control variables. The model is as follows:

$$
Y_{i j}=\gamma_{00}+\gamma_{01}(\text { Sample })_{j}+\gamma_{02}\left(\mathrm{IM} \_\mathrm{BL}\right)_{j}+\zeta_{0 j}+\gamma_{10}(\mathrm{Time})_{i j}+\zeta_{1 j}(\mathrm{Time})_{i j}+\gamma_{20}\left(\mathrm{IM} \_\mathrm{TV}\right)_{i j}+\zeta_{2 j}\left(\mathrm{IM} \_\mathrm{TV}\right)_{i j}+\varepsilon_{i j}
$$

where $\mathrm{BL}=$ baseline (T1 measurement) and $\mathrm{TV}=$ time-varying (deviations from the baseline; $\mathrm{T} 1$ score is subtracted from the scores on subsequent measurement occasions). The coefficient $\gamma_{02}$ shows the effect of intrinsic motivation at baseline score, and the coefficient $\gamma_{20}$ shows the effect of change in intrinsic motivation from baseline. The symbols $\zeta_{i j}$ and $\varepsilon_{i j}$ represent the residual variance at level 2 and level 1, respectively.

The results of the two models are presented in Table 3. In model 1, the effect of time was significant $(\gamma=0.014, p$ $<.001,95 \%$ CI $[0.010,0.018]$ ). Both AIC and BIC showed better values in this model than the model without two intrinsic motivation predictors ( $\mathrm{AIC}=1235.41$ and $\mathrm{BIC}=1293.09)$. The effect of intrinsic motivation score at baseline (IM_BL) was significant $(\gamma=0.62, p<.001,95 \% \mathrm{CI}[0.48,0.75])$. This suggests that children with higher intrinsic motivation scores at $\mathrm{T} 1$ showed higher metacognitive strategy levels at the mean level. Additionally, deviations from the baseline score of intrinsic motivation (IM_TV) were also significant $(\gamma=0.40, p<.001$, $95 \% \mathrm{CI}[0.34,0.46])$, suggesting that children with more growth in intrinsic motivation scores have more increase in metacognitive strategy.

Table 3. Results of multilevel analyses of the effects of intrinsic motivation on metacognitive strategy

\begin{tabular}{lcccc} 
& & Estimates & $S E$ & $95 \%$ CI \\
\cline { 2 - 5 } & Fixed effects & & & \\
& Intercept $\left(\gamma_{00}\right)$ & $0.74^{* * *}$ & 0.24 & {$[0.28,1.20]$} \\
& Sample $\left(\gamma_{01}\right)$ & 0.10 & 0.08 & {$[-0.06,0.26]$} \\
& IM_BL $\left(\gamma_{02}\right)$ & $0.62^{* * *}$ & 0.07 & {$[0.48,0.75]$} \\
& Time $\left(\gamma_{10}\right)$ & $0.014^{* * *}$ & 0.002 & {$[0.010,0.018]$} \\
& IM_TV $\left(\gamma_{20}\right)$ & $0.40^{* * *}$ & 0.03 & {$[0.34,0.46]$} \\
& Radom effects & & & \\
& Intercept $\left(\zeta_{0 j}\right)$ & 0.30 & & \\
& Time $\left(\zeta_{1 j}\right)$ & 0.0003 & & \\
& IM_TV $\left(\zeta_{2 j}\right)$ & 0.01 & & \\
& Within-children $\left(\varepsilon_{i j}\right)$ & 0.15 & & \\
& & & & \\
& & &
\end{tabular}

Note. ${ }^{* * *} p<.001$. 


\section{Discussion}

\subsection{Developmental Changes in Metacognitive Strategy}

This study examined how metacognitive strategies would change. It was hypothesized that metacognitive strategies would increase over elementary school years (Hypothesis 1). Multilevel modeling analyses verified this trend. Children's metacognitive strategy scores increased linearly from 3rd to 5th grade in Sample 1 and from 4th to 6th grade in Sample 2. Thus, Hypothesis 1 was supported.

In general metacognition studies, it was assumed that children's metacognitive functions tend to develop more in the middle to late elementary school years (Veenman, 2012). This trend has been shown in some experimental studies (e.g., Cross \& Paris, 1988; Veenman, Wilhelm, \& Beishuizen, 2004). The results of the present study were consistent with previous findings. Metacognition as a learning strategy (i.e., metacognitive strategy) also seems to develop in the middle to late elementary school years.

The developmental change in metacognitive strategies was not a quadratic but linear increase. This suggests that metacognitive strategies develop equally in the middle to late elementary school years. In some experimental studies (e.g., Dufresne \& Kobasigawa, 1989; Markman, 1979), first and second graders cannot spontaneously use metacognitive strategies. If samples of first and second graders are included in the investigation, then a quadratic change in metacognitive strategy may be found, although there are some difficulties in measuring lower grade children's metacognitive strategy.

\subsection{The Effects of Intrinsic Motivation on Metacognitive Strategy}

In this study, the effects of changes in intrinsic motivation on the changes in metacognitive strategies were tested. It was suggested that intrinsic motivation had impacts on metacognitive strategy in two ways. First, the initial status of intrinsic motivation (i.e., baseline score) was related to the average metacognitive strategy level. Children with higher intrinsic motivation scores at baseline showed higher levels of metacognitive strategy on average over the measurement occasions. Second, the deviations from the baseline of intrinsic motivation were related to changes in metacognitive strategy. This suggests that children who are more intrinsically motivated for daily classes use more metacognitive strategies. Thus, Hypothesis 2, which is the change in intrinsic motivation, is related to changes in metacognitive strategy, was supported.

Metacognitive strategies can be a mediation factor to predict academic achievement. Research literature has examined the relationships between motivational factors and academic achievement. Taylor et al. (2014) revealed that intrinsic motivation predicted later academic achievement by a meta-analysis and longitudinal data. Considering the findings that verified the effect of metacognition on academic achievement (Dent \& Koenka, 2016; Ohtani \& Hisasaka, 2018), metacognitive strategies could mediate these relationships. It is assumed that intrinsically motivated children engage in daily classes using metacognitive strategies, and the use of more metacognitive strategies leads to academic achievement.

It is noteworthy that changes in intrinsic motivation were not found in the present study. Some studies reported a gradual decline in intrinsic motivation from elementary to middle school (A. E. Gottfried, Fleming, \& A. W. Gottfried, 2001). In particular, middle school transition has been highlighted as a risk factor for motivation (Wigfield \& Eccles, 2002). However, this study did not replicate this trend. A plausible reason for this is cultural differences. A developmental decline in intrinsic motivation was mainly found in Western nations. Japanese children may have different trends partly because of teachers' instructional styles or classroom environments. Furthermore, it seems that the decline in intrinsic motivation has not been evident in recent studies. The developmental trend of intrinsic motivation should be examined in more detail.

Another discussion should point to the causal direction between intrinsic motivation and metacognitive strategies. This study assumed that intrinsic motivation affected metacognitive strategies based on previous studies (Ahmed et al., 2013; Yamauchi et al., 1999). However, some studies have proposed that metacognitive strategies could affect motivational factors such as intrinsic motivation or self-efficacy (e.g., Aydin, 2016; Jain \& Dowson, 2009). In daily classes, children who learn by using metacognitive strategies can understand lessons' contents and find interest in the study materials. These experiences can lead to intrinsic motivation. If so, metacognitive strategies should predict intrinsic motivation later. The causal direction should be tested in future studies.

\subsection{Practical Implications}

The findings of this study have some practical implications. First, children's grades should be considered enough when teaching metacognitive strategies for elementary school children. Some educational programs to instruct metacognitive strategies have been developed, and the effects were empirically confirmed for the samples of elementary school children (Dignath et al., 2008; Lee, Capraro, Capraro, \& Bicer, 2018). This study revealed a 
gradual linear increase in metacognitive strategies. If considering the trend, more careful instruction may be suitable for lower grades. For higher grade children, instruction is more effective when focusing on the use and applying the metacognitive strategies they had acquired.

The second point is the effects of intrinsic motivation on metacognitive strategies. Teachers may support children's development in metacognitive strategies by fostering their intrinsic motivation in daily classes. Teaching styles and classroom environments that foster intrinsic motivation have been examined in the literature (e.g., Ohtani, Okada, Ito, \& Nakaya, 2013; Reeve, 2016; Stipek, 2002). The findings may apply to teaching or educational programs to support metacognitive strategies. Zepeda, Hlutkowsky, Partika, and Nokes-Malach (2019) observed teachers' instruction in 6th to 8th-grade classes and proposed three metacognitive support manners: directives, prompting, and modeling. The combination of metacognitive support and motivational support seems to maximize children's development in metacognitive strategies.

\subsection{Limitations}

This study has two main limitations. First, the metacognitive strategy was measured using only a self-reported questionnaire. This method is consistent with off-line metacognition, assessed either before or after engaging in task performance (Veenman et al., 2006). Self-reported measurement has been widely used in metacognitive research and has yielded many findings. However, there are some critiques about self-reported measurement or off-line methods, mainly in terms of its validity (Saraç \& Karakelle, 2017). Future studies should examine whether the findings of this study are replicated by using other measurement methods.

Second, the intervals between measurement occasions were not equal. For example, there were six months from $\mathrm{T} 1$ to T2, whether three months from T2 to T3. These variations were due to the educational setting or school curricula of the participating school. This study dealt with the problem by estimating the effects of time on a monthly basis. However, measurements at equal intervals may be ideal.

\section{Conclusions}

This study provided empirical data to show the developmental change in metacognitive strategies and the effects of intrinsic motivation on the change in a sample of Japanese elementary school children. Generally, older children tend to use more metacognitive strategies. However, some development variations and intrinsic motivation for daily classes play a role in developmental changes in metacognitive strategies. Metacognitive strategies are critical for academic achievement and process. Educational practices and teaching are required to support children to acquire and use metacognitive strategies in academic settings.

\section{Acknowledgments}

This research was supported by JSPS KAKENHI Grant NumberJP20K03369. I express my sincere gratitude to the children and school teachers who participated in this study for their cooperation. Also, I would like to thank Editage (www.editage.com) for English language editing.

\section{References}

Ahmed, W., Van der Werf, G., Kuyper, H., \& Minnaert, A. (2013). Emotions, self-regulated learning, and achievement in mathematics: A growth curve analysis. Journal of Educational Psychology, 105(1), 150-161. https://doi.org/10.1037/a0030160

Allison, P. D. (2009). Fixed effects regression models. Thousand Oaks: Sage. https://doi.org/10.4135/9781412993869

Aydin, S. (2016). An analysis of the relationship between high school students' self-efficacy, metacognitive strategy use and their academic motivation for learn biology. Journal of Education and Training Studies, 4(2), 53-59. https://doi.org/ 10.11114/jets.v4i2.1113

Cross, D. R., \& Paris, S. G. (1988). Developmental and instructional analyses of children's metacognition and reading comprehension. Journal of Educational Psychology, 80(2), 131-142. https://doi.org/10.1037/0022-0663.80.2.131

Dent, A. L., \& Koenka, A. C. (2016). The relation between self-regulated learning and academic achievement across childhood and adolescence: A meta-analysis. Educational Psychology Review, 28(3), 425-474. https://doi.org/10.1007/s10648-015-9320-8

Dignath, C., Büettner, G., \& Langfeldt, H. P. (2008). How can primary school students learn self-regulated learning strategies most effectively?: A meta-analysis on self-regulation training programmes. Educational Research Review, 3(2), 101-129. https://doi.org/10.1016/j.edurev.2008.02.003 
Dufresne, A., \& Kobasigawa, A. (1989). Children's spontaneous allocation of study time: Differential and sufficient aspects. Journal of Experimental Child Psychology, 47(2), 274-296. https://doi.org/10.1016/0022-0965(89)90033-7

Flavell, J. H. (1979). Metacognition and cognitive monitoring: A new area of cognitive-developmental inquiry. American Psychologist, 34(10), 906-911. https://doi.org/10.1037/0003-066X.34.10.906

Gottfried, A. E., Fleming, J. S., \& Gottfried, A. W. (2001). Continuity of academic intrinsic motivation from childhood through late adolescence: A longitudinal study. Journal of Educational Psychology, 93(1), 3-13. https://doi.org/10.1037/0022-0663.93.1.3

Harter, S. (1981). A new self-report scale of intrinsic versus extrinsic orientation in the classroom: Motivational and informational components. Developmental Psychology, 17(3), 300-312. https://doi.org/10.1037/0012-1649.17.3.300

Ichihara, M., \& Arai, K. (2006). Moderator effects of meta-cognition: A test in math of a motivational model. Japanese Journal of Educational Psychology, 54(2), 199-210. [in Japanese] https://doi.org/10.5926/jjep1953.54.2_199

Jain, S., \& Dowson, M. (2009). Mathematics anxiety as a function of multidimensional self-regulation and $\begin{array}{lllll}\text { self-efficacy. } \quad \text { Contemporary } & \text { Educational }\end{array}$ https://doi.org/10.1016/j.cedpsych.2009.05.004

Lee, Y., Capraro, M. M., Capraro, R. M., \& Bicer, A. (2018). A meta-analysis: Improvement of students' algebraic reasoning through metacognitive training. International Education Studies, 11(10), 42-49. https://doi.org/10.5539/ies.v11n10p42

Markman, E. M. (1979). Realizing that you don't understand: Elementary school children's awareness of inconsistencies. Child Development, 50(3), 643-655. https://doi.org/10.2307/1128929

Moshman, D. (2018). Metacognitive theories revisited. Educational Psychology Review, 30(2), 599-606. https://doi.org/10.1007/s10648-017-9413-7

Ohtani, K., \& Hisasaka, T. (2018). Beyond intelligence: A meta-analytic review of the relationship among metacognition, intelligence, and academic performance. Metacognition and Learning, 13(2), 179-212. https://doi.org/10.1007/s11409-018-9183-8

Ohtani, K., Okada, R., Ito, T., \& Nakaya, M. (2013). A multilevel analysis of classroom goal structures' effects on intrinsic motivation and peer modeling: Teachers' promoting interaction as a classroom level mediator. Psychology, 4(8), 629-637. [in Japanese] https://doi.org/ 10.4236/psych.2013.4809

Okada, R. (2019). Peer interaction and intrinsic motivation in elementary school class. Bulletin of Educational Research and Teacher Development of Kagawa University, 39, 35-43. [in Japanese]

Paris, S. G., \& Winograd, P. (1990). How metacognition can promote academic learning and instruction. In B. F. Jones, \& L. Idol (Eds.), Dimensions of thinking and cognitive instruction (pp. 15-51). Hillsdale: Lawrence Erlbaum

Pintrich, P. R. (2003). A motivational science perspective on the role of student motivation in learning and teaching contexts. Journal of Educational Psychology, 95(4), 667-686. https://doi.org/10.1037/0022-0663.95.4.667

Pintrich, P. R., Smith, D. A. F., Garcia, T., \& McKeachie, W. J. (1993). Reliability and predictive validity of the Motivated Strategies for Learning Questionnaire (MSLQ). Educational and Psychological Measurement, 53(3), 801-813. https://doi.org/10.1177/0013164493053003024

Reeve, J. (2016). Autonomy-supportive teaching: What it is, how to do it. In W. C. Liu, J. C. K. Wang, \& R. M. Ryan (Eds.), Building autonomous learners: Perspectives from research and practice using self-determination theory (pp. 129-152). Singapore: Springer. https://doi.org/10.1007/978-981-287-630-0_7

Roebers, C. M., Krebs, S. S., \& Roderer, T. (2014). Metacognitive monitoring and control in elementary school children: Their interrelations and their role for test performance. Learning and Individual Differences, 29, 141-149. https://doi.org/10.1016/j.lindif.2012.12.003

Ryan, R. M., \& Deci, E. L. (2000). Intrinsic and extrinsic motivations: Classic definitions and new directions. Contemporary Educational Psychology, 25(1), 54-67. https://doi.org/10.1006/ceps.1999.1020

Saraç, S., \& Karakelle, S. (2017). On-line and off-line assessment of metacognition. International Electronic 
Journal of Elementary Education, 4(2), 301-315.

Sato, J., \& Arai, K. (1998). The relation between the use of learning strategies, learning goals, and causal attributions. Tsukuba Psychological Research, 20, 115-124. [in Japanese]

Schmeck, R. R. (1988). An introduction to strategies and styles of learning. In R. R. Schmeck (Ed.), Learning strategies and learning (pp. 3-20). New York: Plenum Press. https://doi.org/10.1007/978-1-4899-2118-5_1

Snijders, T., \& Bosker, R. (1999). Multilevel analysis. London, England: Sage

Stipek, D. (2002). Good instruction is motivating. In A. Wigfield, \& J. S. Eccles (Eds.), Development of achievement motivation (pp. 309-332). San Diego, CA: Academic Press. https://doi.org/10.1016/B978-012750053-9/50014-0

Suzuki, G. (2013). Grade-level differences in elementary and middle school students' conceptions of learning: correlation with learning strategy use. Japanese Journal of Educational Psychology, 61(1), 17-31. https://doi.org/10.5926/jjep.61.17 [in Japanese]

Taylor, G., Jungert, T., Mageau, G. A., Schattke, K., Dedic, H., Rosenfield, S., \& Koestner, R. (2014). A self-determination theory approach to predicting school achievement over time: The unique role of intrinsic $\begin{array}{llll}\text { motivation. } & \text { Contemporary } & \text { Educational } & \text { Psychology, }\end{array}$ https://doi.org/10.1016/j.cedpsych.2014.08.002

Vansteenkiste, M., Sierens, E., Soenens, B., Luyckx, K., \& Lens, W. (2009). Motivational profiles from a self-determination perspective: The quality of motivation matters. Journal of Educational Psychology, 101(3), 671-688. https://doi.org/10.1037/a0015083

Veenman, M. V. J. (2012). Metacognition in science education: Definitions, constituents, and their intricate relation with cognition. In A. Zohar, \& Y. J. Dori (Eds.), Metacognition in science education: Trends in current research (pp. 21-36). New York: Springer Science+Business Media. https://doi.org/10.1007/978-94-007-2132-6_2

Veenman, M. V. J., Van Hout-Wolters, B. H. A. M., \& Afflerbach, P. (2006). Metacognition and learning: Conceptual and methodological considerations. Metacognition and Learning, 1, 3-14. https://doi.org/10.1007/s11409-006-6893-0

Veenman, M. V. J., Wilhelm, P., \& Beishuizen, J. J. (2004). The relation between intellectual and metacognitive skills from a developmental perspective. Learning and Instruction, 14(1), 89-109. https://doi.org/10.1016/j.learninstruc.2003.10.004

Wigfield, A., \& Eccles, J. (2002). Students' motivation during the middle school years. In J. Aronson (Ed.), Improving academic achievement: Impact of psychological factors on education (pp. 159-184). New York: Academic Press. https://doi.org/10.1016/B978-012064455-1/50011-7

Yamauchi, H., Kumagai, Y., \& Kawasaki, Y. (1999). Perceived control, autonomy, and self-regulated learning strategies among Japanese high school students. Psychological Reports, 85(3), 779-798. https://doi.org/10.2466/pr0.1999.85.3.779

Young, M. R. (2005). The motivational effects of the classroom environment in facilitating self-regulated learning. Journal of Marketing Education, 27(1), 25-40. https://doi.org/10.1177/0273475304273346

Zepeda, C. D., Hlutkowsky, C. O., Partika, A. C., \& Nokes-Malach, T. J. (2019). Identifying teachers' supports of metacognition through classroom talk and its relation to growth in conceptual learning. Journal of Educational Psychology, 111(3), 522-541. https://doi.org/10.1037/edu0000300

Zimmerman, B. J., \& Martinez-Pons, M. (1990). Student differences in self-regulated learning: Relating grade, sex, and giftedness to self-efficacy and strategy use. Journal of Educational Psychology, 82(1), 51-59. https://doi.org/10.1037/0022-0663.82.1.51

\section{Copyrights}

Copyright for this article is retained by the author(s), with first publication rights granted to the journal.

This is an open-access article distributed under the terms and conditions of the Creative Commons Attribution license (http://creativecommons.org/licenses/by/4.0/). 